\title{
Detection of $P 53$ mutations in different cancer types is improved by cDNA sequencing
}

\author{
SYLWESTER PIASKOWSKI $^{1 *}$, IZABELA ZAWLIK $^{1 *}$, MALGORZATA SZYBKA $^{2}$, \\ DOMINIKA KULCZYCKA-WOJDALA ${ }^{2}$, EWELINA STOCZYNSKA-FIDELUS ${ }^{1}$, MICHAL BIENKOWSKI ${ }^{1}$, \\ TADEUSZ ROBAK ${ }^{3}$, RENATA KUSINSKA $^{4}$, DOROTA JESIONEK-KUPNICKA ${ }^{2}$, \\ RADZISLAW KORDEK ${ }^{2}$, PIOTR RIESKE ${ }^{1}$ and PAWEL P. LIBERSKI ${ }^{1}$

\begin{abstract}
${ }^{1}$ Department of Molecular Pathology and Neuropathology, Chair of Oncology, Medical University of Lodz, 92-216 Lodz; ${ }^{2}$ Department of Pathology, Chair of Oncology, Medical University of Lodz, 93-509 Lodz;

${ }^{3}$ Department of Hematology, Medical University of Lodz, Poland Department of Hematology, Medical University of Lodz and Copernicus Memorial Hospital, 93-510 Lodz, ${ }^{4}$ Department of Pathology, Medical University of Lodz, Copernicus Memorial Hospital, 93-509 Lodz, Poland
\end{abstract}

Received January 29, 2010; Accepted April 14, 2010

DOI: 10.3892/ol_00000125

\begin{abstract}
Recently published data show discrepancies between P53 cDNA and DNA sequencing results in glioblastoma, colorectal cancer and pleomorphic xanthoastrocytoma. We hypothesized that similar discrepancies are observed in other types of human cancers. Using DNA and cDNA direct sequencing, we analyzed 40 cases of invasive breast duct carcinoma, 23 cases of acute myeloblastic leukaemia, 12 cases of astrocytoma and 40 cases of soft tissue sarcoma for P53 mutations. Additionally, we used real-time quantitative PCR to estimate the normalized relative $P 53$ expression. In the comparative study, the $P 53$ mutation was detected more frequently when using cDNA sequencing than DNA sequencing in all of the cancer types. Furthermore, several samples presented missense P53 mutations, with visible wild-type nucleotide on the DNA sequence. In contrast, elimination of the wild-type allele or selective overproduction of the mutated allele was observed on the cDNA sequence. P53 expression was not significantly different between the cases with or without P53 mutations. These results indicate that cDNA sequencing improves the detection of P53 mutations in these cancers. We suggest that the true incidence of P53 mutations in these cancers is underestimated at the DNA level, and evaluation of the alteration should be carried out using cDNA analysis.
\end{abstract}

Correspondence to: Dr Izabela Zawlik, Department of Molecular Pathology and Neuropathology, Chair of Oncology, Medical University of Lodz, 8/10 Czechoslowacka str., 92-216 Lodz, Poland E-mail: izazawlik@yahoo.com

*Contributed equally

Key words: P53, mutation, expression, DNA, cDNA, sequencing

\section{Introduction}

The $P 53$ tumor suppressor gene is one of the most commonly mutated genes in human cancers (1). The majority of P53 mutations are missense mutations, generally located in the central domain of the P53 coding region (exons 5-8) $(2,3)$. Other tumor suppressor genes predominantly contain nonsense or other truncation-producing alterations (4-6).

P53 mutations have been identified in a wide variety of human cancers, including invasive breast duct carcinoma (IDC), acute myeloblastic leukaemia (AML), astrocytoma and soft tissue sarcoma (STS). P53 mutations have been identified in $15-50 \%$ of IDC (7), in $4.5-9 \%$ of AML $(8,9)$, in $12.5-59 \%$ of astrocytoma $(10,11)$ and in $11-20 \%$ of STS $(12,13)$. The wide range of P53 mutation frequencies in these cancers may be due to cancer tissue heterogeneity, differences in the examined population or the technical approach employed. The presence of P53 mutations may have both prognostic and therapeutic consequences. Therefore, the use of the optimal method for the determination of P53 mutations is critical. The P53 mutation has been reported to be of prognostic importance in breast cancer, AML, astrocytoma and STS (8,14-17). Thus, detection of the actual incidence of $P 53$ mutations is essential in these cancers.

Methods used for the detection of P53 mutations are based either on genomic DNA or mRNA as a template $(11,12,15)$. The most widely used methods are based on DNA sequencing. However, few studies exist that compare sequencing assays by using both RNA and DNA targets (18-22). Recently, it was demonstrated that the detection of P53 mutations has improved, and P53 mutations are detected more frequently at the mRNA level (using cDNA sequencing) than at the DNA level in glioblastomas, colorectal cancer and pleomorphic xanthoastrocytoma (20-22). Therefore, whether similar discrepancies occur in other types of human cancers was investigated. For this study, IDC, AML, astrocytoma and STS were selected as the cancers presenting frequent P53 mutations. The P53 gene status was evaluated by means of 
Table I. Primer sequences used for the P53 gene sequencing.

\begin{tabular}{|c|c|c|}
\hline Region & PCR primer & Sequencing primer \\
\hline Exon 5 & $\begin{array}{l}5^{\prime}-\text { ttccacaccccegcceggca-3' } \\
5^{\prime} \text {-accctgggcaaccagccetg-3' }\end{array}$ & $\begin{array}{l}\text { 5'-caagcagtcacagcacatga-3' } \\
\text { 5'-aaccagccetgtcgtctct-3' }\end{array}$ \\
\hline Exon 6 & $\begin{array}{l}\text { 5'-acagggctggttgcccaggg-3' } \\
\text { 5'-agttgcaaaccagacctcag-3' }\end{array}$ & $\begin{array}{l}\text { 5'-caggcctctgattcctcact-3' } \\
5^{\prime} \text {-agacctcaggcggctcatag-3' }\end{array}$ \\
\hline Exon 7 & $\begin{array}{l}\text { 5'-actggcctcatcttgggcct-3' } \\
5^{\prime} \text {-gtcagaggcaagcagaggct-3' }\end{array}$ & $\begin{array}{l}\text { 5'-atctcctaggttggctctga-3' } \\
\text { 5'-tggcaagtggctcctgacct-3' }\end{array}$ \\
\hline Exon 8 & $\begin{array}{l}\text { 5'-taaatgggacaggtaggacc-3' } \\
5^{\prime} \text {-tccaccgcttcttgtcctgc-3' }\end{array}$ & $\begin{array}{l}5^{\prime}-\text { ctcttttcctatcctgagta-3' } \\
5^{\prime}-\text { ctgcttgcttaccetgctta-3' }\end{array}$ \\
\hline cDNA exons 5-8 & $\begin{array}{l}5^{\prime} \text {-gtgcagctgtgggttgatt-3' } \\
5^{\prime} \text {-gcagtgctcgcttagtgctc-3' }\end{array}$ & $\begin{array}{l}\text { 5'-gccatctacaagcagtcaca-3' } \\
5 \text { '-ccetttcttgcggagattct-3' }\end{array}$ \\
\hline
\end{tabular}

both cDNA and DNA sequencing and real-time quantitative RT-PCR.

\section{Materials and methods}

Tumor samples. The study included 40 patients with IDC, 23 patients with AML, 12 patients with astrocytoma (7 cases of anaplastic astrocytoma WHO grade III, 5 cases of diffuse astrocytoma WHO grade II) and 40 patients with STS. The patients with STS, IDC and astrocytoma were diagnosed at the Department of Pathology, Medical University of Lodz. The patients with AML were diagnosed at the Department of Haematology, Medical University of Lodz. Approval for the study was provided by the Bioethical Committee of Medical University of Lodz (No. RNN/53/08/KE). Patient consent was obtained from each individual included in the study.

DNA and RNA isolation. Isolation was performed using snapfrozen tissues stored at $-80^{\circ} \mathrm{C}$ and fresh or frozen leucocytes of peripheral blood or bone marrow cells obtained from the patients, prior to the initiation of the therapy. DNA and RNA were co-extracted by means of the Macherey-Nagel DNA/ RNA purification kit. RNA samples were treated with DNase. RNA and DNA concentrations were measured spectrophotometrically. Total RNA (100 ng) was reverse-transcribed into single-stranded cDNA in a final volume of $40 \mu \mathrm{l}$ containing $50 \mathrm{mM}$ DTT, $1.5 \mu \mathrm{g}$ oligo(dT), $0.5 \mathrm{mM}$ dNTP, 40 units RNase inhibitor and 200 units M-MLV reverse transcriptase (Promega).

P53 DNA and cDNA sequencing. Exons 5-8 of the P53 gene were amplified by PCR as previously described and sequenced using the dideoxy termination method and the SequiTherm Excel DNA Sequencing kit (Epicentre Technologies) (20,23). The primer sequences are shown in Table I. DNA and cDNA sequence alterations were reconfirmed by a repeated analysis of isolated DNA and RNA, respectively. To verify the results of sequencing, the semi-quantitative densitometric analysis was performed as previously described (21). The intensity of wild-type and mutated bands was estimated by comparison with neighbouring bands in the same sequencing lane, and used as a reference (21).
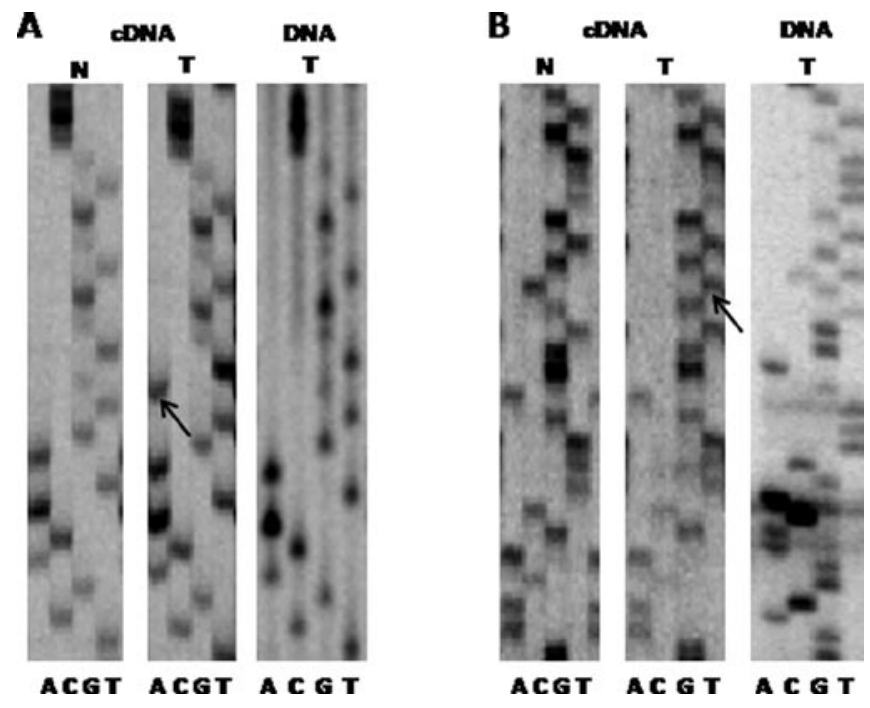

Figure 1. P53 DNA and cDNA sequencing. (A) cDNA sequencing showing a mutation (arrow) and DNA analysis confirming the presence of the wild-type nucleotide only (AML, case no. 2; Table II). (B) cDNA sequencing showing only the mutated nucleotide (arrow) and DNA presenting a missense mutation with visible wild-type nucleotide (STS, case no. 9; Table II). N, normal tissue (blood); T, tumor sample.

Real-time quantitative RT-PCR. Real-time quantitative RT-PCR was performed on a Rotor Gene 6000 instrument (Corbett, Life Sciences, Australia) for the P53 gene (TaqMan ${ }^{\circledR}$ Gene Expression Assays no. Hs00153340_m1 and no. Hs00153349_ $\mathrm{m} 1$ ), with GAPDH $\left(\right.$ TaqMan $^{\circledR}$ Gene Expression Assays no. Hs99999905_m1) as a reference gene for the normalization of the target gene expression levels. The normalized relative P53 expression level in an unknown sample vs. the control sample was calculated using the method described by Pfaffl et al with the blood of two healthy donors as control tissue (24).

Statistical analysis. The differences in P53 expression levels for a particular cancer type and for all cancer types together were evaluated by the Mann-Whitney $U$ test. Statistical significance was set at $\mathrm{P} \leq 0.05$. The statistical analysis was performed with Stat-View for Windows 5.01 Software ${ }^{\circledR}$ (SAS Institute Inc., Cary, NC, USA). 
Table II. Results of P53 gene mutations in the cancers examined.

\begin{tabular}{llllll}
\hline Case no. & $\begin{array}{c}\text { Mutation and } \\
\text { polymorphism }\end{array}$ & Exon & Codon & Effect & cDNA \\
\hline
\end{tabular}

Invasive breast

duct carcinoma

1

2

3

4

5

6

7

8

Acute myeloblastic

leukaemia

1
2
3

Astrocytoma

1
2
3

Soft tissue sarcoma

1
2
3
4
5
6
7
8

9
10

Deletion
GGC $>$ AGC
CGT $>$ CAT
GAC $>$ TAC
Deletion
CGT $>$ CTT
ATG $>$ AAG
CGT $>$ CTT

\author{
CGA >CGG polymorphism \\ GTG $>$ ATG \\ CGG>GGG
}
CGT>TGT
Insertion
Deletion

CGC $>$ CAC
GGC $>$ AGC
CGT $>$ TGT
CGA $>$ CGG polymorphism
CCT $>$ CTT
AGT $>$ AAA
CGG $>$ CAG
CGA $>$ CGG polymorphism
CGA $>$ CGG polymorphism
CGG $>$ CAG
CCC $>$ CCG polymorphism
CGA $>$ CGG polymorphism
CGT $>$ TGT
GTG $>$ ATG

172
245
273
281
274
273
237
273

245

273

281

274

273

237

273

del42a
Gly $>$ Ser
Arg $>$ His
Asp $>$ Tyr
del6a
Arg $>$ Leu
Met $>$ Lys
Arg $>$ Leu

Only MT
Only MT

Only MT

MT $>$ WT

MT

Only MT

Only MT

Only MT

\section{216}

267

273

217

250

7

175

245

273

231

278

215

248

213

213

248

177

213

273

216
Arg $>$ Arg

Val $>$ Met

Arg>Gly

Arg $>$ Cys
ins6a
del187c

$\begin{array}{cc}\text { A/G } & \text { A/G } \\ \text { Only MT } & \text { WT } \\ \text { MT=WT } & \text { MT=WT } \\ & \\ \text { MT=WT } & \text { MT=WT } \\ \text { MT } & \text { MT } \\ \text { Only MT } & \text { WT }\end{array}$

Arg $>\mathrm{His}$

Gly $>$ Ser

Arg $>$ Cys

Arg $>$ Arg

Pro $>$ Leu

Ser $>$ Lys

Arg>Gln

Arg $>$ Arg

Arg $>$ Arg

Arg $>$ Gln

Pro $>$ Pro

Arg $>$ Arg

Arg $>$ Cys
$\mathrm{MT}=\mathrm{WT}$
MT $>$ WT
$\mathrm{MT}=\mathrm{WT}$
G/G
MT
MT $>$ WT
MT
$\mathrm{G} / \mathrm{G}$
A/G
Only MT
G/G
G/G

Only MT

Only MT

MT, mutated template; MT>WT, prevalence of mutated template; WT, wild-type template; MT=WT, equal amount of mutated and wild-type template; del, deletion; ins, insertion. a, first base of the codon; c, third base of the codon.

\section{Results}

cDNA sequencing in IDC discerns the P53 mutation more frequently than DNA sequencing. Sequencing of DNA showed P53 mutations in 3 of the 40 analyzed IDC cases $(7.5 \%)$. Sequencing of cDNA showed the presence of a $P 53$ mutation in 5 more cases, i.e., 8 of 40 (20\%). One deletion and 4 missense mutations were found on the cDNA sequencing, but not on the DNA sequencing (cases nos. 1, 2, 6, 7 and 8). Three cases showed a P53 mutation on both the DNA and cDNA sequence: 1 missense mutation with a visible wild-type nucleotide on the DNA sequence showed only the mutated cDNA template with the elimination of wild-type mRNA (case no. 3); 1 missense mutation with visible wild-type nucleotide on the DNA sequence showed a higher ratio of mutated to wild-type on the cDNA template (case no. 4) and 1 case did not differ in the presence of a mutation between the DNA and cDNA sequence (case no. 5; Table II). The detection of P53 mutations was found to be 2.7 times more frequent in IDC on the cDNA vs. the DNA sequence.

cDNA sequencing in AML discerns the P53 mutation more frequently than DNA sequencing. The P53 DNA sequencing results for AML, in part, were previously reported (25). Sequencing of DNA showed the presence of a P53 mutation in 1 of the 23 AML cases (4.3\%). Sequencing of cDNA showed a P53 mutation in 1 more case, i.e., 2 of 23 (8.7\%). A missense mutation based only on cDNA was noted in case no. 2 ; in case no. 3 no difference in the presence of mutations between the DNA and cDNA sequence was observed and case 1 showed 
the $\mathrm{A} / \mathrm{G}$ polymorphism at codon 213 on both the cDNA and DNA sequences (Table II). The detection of the P53 mutation was found twice as frequently in AML using cDNA vs. DNA sequencing.

cDNA sequencing in astrocytoma discerns the P53 mutation more frequently than DNA sequencing. Sequencing of DNA showed the presence of P53 mutations in 2 of the 12 astocytoma cases (16.7\%). Sequencing of cDNA showed P53 mutations in 1 more case, i.e., 3 of 12 (25\%). One mutation (deletion) was found based only on cDNA sequencing (case no. 3), and 2 mutations did not differ between the DNA and cDNA sequence (Table II). The detection of P53 mutations was 1.5 times more frequent in astrocytoma using cDNA vs. DNA sequencing.

cDNA sequencing in STS discerns the P53 mutation more frequently than DNA sequencing. The P53 DNA sequencing results in STS, in part, were previously reported (26). Sequencing of DNA showed the presence of P53 mutations in 8 of the 40 STS cases (20\%). Sequencing of cDNA showed a P53 mutation in 1 more case, i.e., 9 of 40 (22.5\%). One missense mutation was found based only on cDNA sequencing (case no. 8), and 2 missense mutations with a visible wild-type nucleotide on DNA sequence showed only the mutated cDNA template with the elimination of wild-type mRNA (cases no. 9 and 10; Table II). Six missense mutations did not differ between the DNA and cDNA sequences. Six polymorphism sites were found on both the cDNA and DNA sequences (Table II). The detection of P53 mutations was 1.1 times more frequent in STS using cDNA sequencing than using DNA sequencing.

cDNA sequencing in all of the cancer types discerns the P53 mutation more frequently than DNA sequencing. A total of 14 mutations were found in both the cDNA and genomic DNA sequences. Eight additional mutations (6 missense and 2 deletions) were found based only on cDNA sequencing (Table II). No mutations were found only on the DNA sequence. P53 mutations were detected more frequently in the examined cancer types when the cDNA sequencing assay was used, i.e., $8.3 \%$ and $5.3 \%$ of P53 mutations were found based on the cDNA and DNA sequence, respectively. The highest difference in the frequency of P53 mutation detection using cDNA and DNA sequencing assay was observed in IDC. Furthermore, 4 of the 10 samples presented a missense P53 mutation with visible wild-type nucleotide on the DNA sequence which showed elimination of the wild-type allele (3 samples) or selective overproduction of the mutated allele on the cDNA sequence (1 sample) (Table II).

P53 expression did not differ between cases with and without P53 mutations. The mean P53 mRNA level did not increase in any of the cancers examined in comparison to the control blood samples (the mean level for each type of cancer was $\sim 1$ ). P53 mRNA levels were compared between the two groups: cases with P53 mutations and those lacking a P53 mutation. $P 53$ expression was not significantly different between the two groups $(\mathrm{P}>0.05$ for a particular cancer type and for all cancer types together).
P53 expression was 2 -fold higher, but not significantly, in samples that presented a missense P53 mutation with a visible wild-type nucleotide on DNA and with the elimination of the wild-type allele or selective overproduction of the mutated allele on the cDNA sequence (mean fold 1.9) than in samples which showed a similar level of mutated and wildtype template on both the DNA and cDNA sequence (mean fold 0.9).

\section{Discussion}

This is a comparative study of two sequencing assays, cDNA and DNA sequencing, in IDC, AML, astrocytoma and STS. An analysis of these cancers supports our previous data for glioblastoma, colorectal cancer and pleomorphic xanthoastrocytoma. Subsequently, the detection of P53 mutations is improved and more frequent at the mRNA than at the DNA level (20-22). Our previous comparative studies showed that the selective promotion of the mutated P53 mRNA in glioblastoma samples with $P 53$ heterozygous missense mutations, and P53 missense mutations in colorectal cancer and pleomorphic xanthoastrocytoma were more frequently detected using cDNA vs. DNA sequencing (20-22). A comparative study of P53 cDNA and DNA sequencing in colorectal cancer by Forslund $e t$ al showed a higher, although not significant, frequency of $P 53$ mutation detection using cDNA sequencing as opposed to DNA sequencing (10 mutations were found based only on the cDNA sequence and 3 mutations were found based only on the DNA sequence) (19).

In the present study, the P53 mutation was detected more frequently in all of the cancer types when the cDNA sequencing assay was used, whereas a total of 8 additional mutations (6 missense and 2 deletions) were found based only on the cDNA sequence. No mutations were detected on the DNA sequence alone. The highest difference in the frequency of P53 mutation detection using the cDNA and DNA sequencing assay was observed in IDC. Moreover, several samples presented a missense P53 mutation with a visible wild-type allele on DNA sequencing, that may have originated from infiltrating or surrounding normal cells, or may have been a heterozygous missense mutation. In contrast, elimination of the wildtype allele or selective overproduction of the mutated allele was noted on the cDNA sequence. A similar phenomenon was observed in our previous study of glioblastoma with heterozygous missense mutations, in which elimination of the wild-type allele was observed. In addition, a study of breast cancer with missense mutations also presented the wild-type DNA nucleotide, which originated from infiltrating or surrounding normal cells in which a higher tumor-specific signal for RNA than for DNA was detected $(18,20)$. The reason for the discrepancies between DNA and cDNA P53 analysis may be, at least in part, the genotypical heterogeneity of cells located in cancer tissues $(21,22)$. The contamination of tumor samples by cells without P53 mutations (normal and/or neoplastic) results in difficulties in the detection of P53 mutations using DNA analysis. In a sample containing less than $25-30 \%$ of tumor cells, $P 53$ mutation detection using direct DNA sequencing is almost impossible $(21,27)$. However, for cases presenting heterozygous missense mutations, the mechanisms responsible for the selective overexpression of 
mutated P53 mRNA require further scrutiny. The investigation of glioblastoma with heterozygous missense mutations enabled us to propose three possible hypotheses to explain these discrepancies: i) the silencing of wild-type mRNA transcription; ii) the degradation of wild-type mRNA; and iii) the selective overproduction of mutated mRNA (21). The mechanism(s) which favour the mutated type of P53 mRNA have yet to be determined. Nevertheless, our approach, based on cDNA analysis, increased P53 mutation detectability for the examined cancers. Moreover, we cannot exclude the hypothesis that the up-regulation of the mutated P53 allele co-exists with the silencing of the wild-type allele in these cancers. The use of an optimal method for the determination of P53 mutations is important, particularly for cancers in which the presence of $P 53$ mutations is a diagnostic, predictive and prognostic factor. It should be kept in mind that, although we employed the cDNA sequencing assay in this study, it is very sensitive in the detection of the mutated template since it does not allow for the detection of all types of mutations $(18,28)$.

In colorectal cancer an increased mRNA P53 expression and no difference in the mRNA P53 expression between cancers with or without a P53 mutation has been reported (21). In our study, the P53 mRNA level did not increase in any type of cancer examined and was not significantly different between cases with or without a P53 mutation.

In conclusion, we suggest that the true incidence of P53 mutations in the examined cancers is underestimated at the DNA level, and evaluation of the gene alteration should be conducted using cDNA analysis. The approach adopted by the authors was based on cDNA analysis and resulted in an increased detection of P53 mutations in all types of analyzed cancers. Thus, we suggest that $P 53$ cDNA sequencing be applied for these cancers to increase P53 mutation detectability.

\section{Acknowledgements}

This study was supported by the Ministry of Science and Higher Education projects no. N N 401020635 and no. N N 4011558 33. Mrs. Grace Dudaniec is kindly acknowledged for the language assistance.

\section{References}

1. Vogelstein B, Lane D and Levine AJ: Surfing the p53 network. Nature 408: 307-310, 2000

2. Hollstein M, Hergenhahn M, Yang Q, Bartsch H, Wang ZQ and Hainaut P: New approaches to understanding p53 gene tumour mutation spectra. Mutat Res 31: 199-209, 1999.

3. Nigro JM, Baker SJ, Preisinger AC, et al: Mutations in the p53 gene occur in diverse human tumour types. Nature 342: 705-707, 1989.

4. Laurent-Puig P, Béroud C and Soussi T: APC gene: database of germline and somatic mutations in human tumors and cell lines. Nucleic Acids Res 26: 269-270, 1998.

5. Heim RA, Kam-Morgan LN, Binnie CG, et al: Distribution of 13 truncating mutations in the neurofibromatosis 1 gene. Hum Mol Genet 4: 975-981, 1995 .

6. Valverde JR, Alonso J, Palacios I and Pestaña A: RB1 gene mutation up-date, a meta-analysis based on 932 reported mutations available in a searchable database. BMC Genet 6: 53, 2005.

7. Elledge RM and Allred DC: The p53 tumour suppressor gene in breast cancer. Breast Cancer Res Treat 32: 39-47, 1994.

8. Nakano Y, Naoe T, Kiyoi H, et al: Prognostic value of p53 gene mutations and the product expression in de novo acute myeloid leukaemia. Eur J Haematol 65: 23-31, 2000.
9. Stirewalt DL, Kopecky KJ, Meshinchi S, Appelbaum FR, Slovak ML, Willman CL and Radich JP: FLT3, RAS and TP53 mutations in elderly patients with acute myeloid leukaemia. Blood 97: 3589-3595, 2001

10. Thangnipon W, Mizoguchi M, Kukita Y, Inazuka M, Iwaki T, Fukui M and Hayashi K: Distinct pattern of PCR-SSCP analysis of p53 mutations in human astrocytomas. Cancer Lett 141: 195-201, 1999.

11. Ohgaki H, Dessen P, Jourde B, et al: Genetic pathways to glioblastoma: a population-based study. Cancer Res 64: 6892-6899, 2004.

12. Taubert H, Würl P, Bache M, et al: The p53 gene in soft tissue sarcomas: prognostic value of DNA sequencing versus immunohistochemistry. Anticancer Res 18: 183-187, 1998.

13. Patterson H, Gill S, Fisher C, et al: Abnormalities of the p53 MDM2 and DCC genes in human leiomyosarcomas. Br J Cancer 69: 1052-1058, 1994

14. Pharaoh PD, Day NE and Caldas C: Somatic mutations in the p53 gene and prognosis in breast cancer: a meta-analysis. Br J Cancer 80: 1968-1973. 1999.

15. Sjögren $S$, Inganäs $M$, Norberg $T$, Lindgren $A$, Nordgren $H$, Holmberg L and Bergh J: The p53 gene in breast cancer: prognostic value of complementary DNA sequencing versus immunohistochemistry. J Natl Cancer Inst 88: 173-182, 1996.

16. Peraud A, Kreth FW, Wiestler OD, Kleihues P and Reulen HJ: Prognostic impact of TP53 mutations and P53 protein overexpression in supratentorial WHO grade II astrocytomas and oligoastrocytomas. Clin Cancer Res 8: 1117-1124, 2002.

17. Taubert H, Meye A and Würl P: Prognosis is correlated with p53 mutation type for soft tissue sarcoma patients. Cancer Res 56: 4134-4136, 1996.

18. Williams C, Norberg T, Ahmadian A, et al: Assessment of sequence-based p53 gene analysis in human breast cancer: messenger RNA in comparison with genomic DNA targets. Clin Chem 44: 455-462, 1998.

19. Forslund A, Kressner U, Lönnroth C, Andersson M, Lindmark G and Lundholm K: P53 mutations in colorectal cancer assessed in both genomic DNA and cDNA as compared to the presence of p53 LOH. Int J Oncol 21: 409-415, 2002.

20. Szybka M, Zawlik I, Kulczycka D, et al: Elimination of wild-type P53 mRNA in glioblastomas showing heterozygous mutations of P53. Br J Cancer 98: 1431-1433, 2008.

21. Szybka M, Zakrzewska M, Rieske P, et al: cDNA sequencing improves the detection of P53 missense mutations in colorectal cancer. BMC Cancer 11: 278, 2009.

22. Zakrzewska M, Szybka M, Biernat W, Papierz T, Rieske P, Liberski PP and Zakrzewski K: Prevalence of mutated TP53 on cDNA (but not on DNA template) in pleomorphic xanthoastrocytoma with positive TP53 immunohistochemistry. Cancer Genet Cytogenet 193: 93-97, 2009.

23. Zakrzewska M, Wojcik I, Zakrzewski K, et al: Mutational analysis of hSNF5/INI1 and P53 genes in choro id plexus carcinomas. Cancer Genet Cytogenet 156: 179-182, 2005.

24. Pfaffl MW, Horgan GW and Dempfle L: Relative expression software tool (REST) for group-wise comparison and statistical analysis of relative expression results in real-time PCR. Nucleic Acids Res 30: e36, 2002.

25. Wojcik I, Szybka M, Golanska E, Rieske P, Blonski JZ, Robak T and Bartkowiak J: Abnormalities of the P53, MDM2, BCL2 and BAX genes in acute leukemias. Neoplasma 52: 318-324, 2005.

26. Rieske P, Bartkowiak JK, Szadowska AM, Olborski B, Harezga-Bal B and Debiec-Rychter M: A comparative study of P53/MDM2 gene alterations and P53/MDM2 protein immunoreactivity in soft-tissue sarcomas. J Exp Clin Cancer Res 18: 403-416, 1999.

27. Leitner T, Halapi E, Scarlatti G, Rossi P, Albert J, Fenyö EM and Uhlén M: Analysis of heterogenous viral populations by direct DNA sequencing. Bio Techniques 15: 120-126, 1993.

28. Singer G, Stöhr R, Cope L, et al: Patterns of p53 mutations separate ovarian serous borderline tumors and low- and highgrade carcinomas and provide support for a new model of ovarian carcinogenesis: a mutational analysis with immunohistochemical correlation. Am J Surg Pathol 29: 218-224, 2005. 